\title{
No Association Between Lipid Profiles and Acne Vulgaris
}

\author{
Khairina Nasution, Imam Budi Putra, Nelva Karmila Jusuf \\ Department of Dermatology and Venereology, Faculty of Medicine, Universitas Sumatera Utara, Medan, Indonesia
}

Background: Acne vulgaris is a chronic inflammation of pilosebaceous follicle that can spontaneously heal with clinical manifestations such as blackhead, papules, pustules, nodule, and cyst on the face, upper chest, arms, and back. Until now, the effect of lipid metabolism on sebaceous gland secretions in the pathogenesis of acne vulgaris is still under research.

Materials and Methods: An analytic observational study with cross sectional design involving 30 acne vulgaris and 30 control subjects was conducted. Blood samples were taken from subjects and lipid profile levels were measured. The data were then statistically analyzed.

Results: From this research, there was no significant association between lipid profiles with acne vulgaris. There was not any significant difference between the acne vulgaris and the control subjects for total cholesterol, High Density Lipoprotein (HDL), Low Density Lipoprotein (LDL) and triglyceride levels ( $p>0.05)$.

Conclusion: There is no significant association between lipid profiles levels and acne vulgaris.

Keywords: acne vulgaris, lipid profiles, total cholesterol, HDL, LDL, triglyceride

\section{Introduction}

Acne vulgaris is a chronic inflammation of pilosebaceous follicle that can spontaneously heal with clinical manifestations such as blackhead, papule, pustule, nodule, and cyst. Acne vulgaris can affect face, upper chest, arms and back with highest prevalence in teenager. A retrospective study on acne vulgaris patient in Haji Adam Malik General Hospital Medan showed that the majority of patients are women aged 16 to 20 years old. ${ }^{1-8}$

Pathogenesis of acne vulgaris is complex. The effect of lipid metabolism on sebaceous gland secretions in the pathogenesis of acne vulgaris is still under research.

Date of submission: April 12, 2018

Last Revised: June 4, 2018

Accepted for publication: June 5, 2018

Corresponding Author:

Khairina Nasution

Department of Dermatology and Venereology

Faculty of Medicine, Universitas Sumatera Utara

Jl. Doktor Mansyur No.5 Medan Baru, Medan, Sumatera Utara, Indonesia

E-mail: khairina_nst@yahoo.com
From the general observation on western population with acne vulgaris, it implies the role of eating habit, energy consumption and food complexity as causal factors of acne vulgaris. Lipid metabolism is not just about food processing or diet, but also a result of interaction between eating habit and genetic. ${ }^{9}$

Research on association between lipid blood profiles with acne vulgaris has not been widely reported. Several studies have shown that lipid profiles in women suffering from acne vulgaris are increased for total cholesterols and Low Density Lipoprotein (LDL), and decreased for High Density Lipoprotein (HDL) levels. In the contrary, another study reported that there was not any significant difference 
of total cholesterol and triglyceride between acne vulgaris and control subjects, but there was significant decrease of HDL and increase of LDL levels in severe acne vulgaris subjects. ${ }^{10,11}$

\section{Materials and methods}

An analytic observational study with cross sectional design was conducted. Thirty acne vulgaris and 30 control subjects from Flora School of Nursing, aged more than 14 years old, who signed informed consent, were recruited. The exclusion criteria in this study were pregnant, lactating, oral contraception, hormonal therapy, medication that affect lipid metabolism and history of heart disease. This study was conducted after obtaining approval from Research Ethic Commission of Faculty of Medicine Universitas Sumatera Utara (Number: 409/TGL/KEPK FK USU-RSUP HAM 2017).

Subjects' identity and medical record were documented. Physical and dermatology examination were conducted. Before the blood sampling, subjects were instructed to fast at least in 8-12 hours. The blood samples were taken to measure lipid profile level. The blood samples were then inserted into coded tubes and left to coagulate in 2-5 minutes. The frozen blood samples were centrifuged for 5-10 minutes at $4000 \mathrm{rpm}$, then the serum was separated and measured for total cholesterol, HDL, LDL and triglyceride levels.

The obtained data were analyzed using data processing software. The data were statistically analyzed to examine the association between lipid profiles and acne vulgaris. Difference of total cholesterol, HDL and LDL levels between the acne vulgaris and the control subjects were statistically analyzed as well.

\section{Results}

Subjects aged range of 18-22 years old, resided in the same city, had similar variety of diets, had mild or moderate acne vulgaris, were recruited. Lipid profiles in acne vulgaris and control groups, including total cholesterol, HDL, LDL and triglycerides levels, were obtained. The mean of total cholesterol levels in acne vulgaris group was $185.48 \pm 32.93$ $\mathrm{mg} / \mathrm{dL}$ while in control group was $191.41 \pm 36.49 \mathrm{mg} / \mathrm{dL}$. These means were in normal range. Statistical data analysis using t-test showed there was no significant difference between total cholesterol levels in acne vulgaris and control groups ( $p=0.511, p>0.05$ ).
The mean of HDL levels in acne vulgaris group was $59.00 \pm 10.22 \mathrm{mg} / \mathrm{dL}$ while in control group was $55.83 \pm 8.57$ $\mathrm{mg} / \mathrm{dL}$. These means were in normal range. Statistical data analysis using t-test showed no significant difference between HDL levels in acne vulgaris and control groups $(p=0.198, p>0.05)$.

The mean of LDL levels in acne vulgaris group was, which was $114.41 \pm 25.45 \mathrm{mg} / \mathrm{dL}$ while in control group was $120.31 \pm 34.21 \mathrm{mg} / \mathrm{dL}$. , These means were in normal range. Statistical data analysis using t-test showed no significant difference between LDL levels in acne vulgaris and control groups ( $p=0.542, p>0.05$ ).

The mean triglyceride levels in acne vulgaris group was $70.47 \pm 24.251 \mathrm{mg} / \mathrm{dL}$ while in control group was $76.33 \pm 48.124 \mathrm{mg} / \mathrm{dL}$. These means were in normal range. Statistical data analysis using Mann-Whitney test showed no significant difference between triglyceride levels in acne vulgaris and control groups $(p=0.947, p>0.05)$.

\section{Discussion}

Lipid profiles can be influenced by various factors such as diet, weight, physical activities, age and genetic. Various results in association of lipid profiles between triglyceride levels in acne vulgaris and control groups, have been published. Current results showed no significant difference between lipid profiles of acne vulgaris and control groups, which are in accordance with previous report. ${ }^{12}$ In contrary, some report showed a significant difference in lipid profile levels between acne vulgaris and control subjects $(p<0.001) .{ }^{13}$ Several studies that were done in China and Brazil showed association between lipid profile with acne vulgaris. ${ }^{10,14}$ Furthermore, other study on 90 female subjects with severe acne and 90 control subjects showed significant difference between lipid profiles of acne vulgaris patients compared with control. ${ }^{15}$

The effect of lipid metabolism in sebum synthesis correlated with pathogenesis of acne vulgaris is still under study. Observation in western population with acne vulgaris showed the eating habit, energy consumption and food complexity are causing factors of acne vulgaris. Lipid metabolism is not only affected by food processing or diet. It is also affected by race, eating habit, environment and genetic $^{9,12}$

Although, subjects with severe acne vulgaris was not included in current study, a previous report showed that the lipid profile levels of acne vulgaris subjects were lower than 
the normal subjects. ${ }^{14}$ Literatures showed little evidence on the role of lipid synthesis in sebum secretion and development of acne vulgaris. ${ }^{9}$ Since there is no significant difference of lipid profile in acne vulgaris and control subject groups, the effect of serum lipid concentration was suggested to be influenced by the environment, genetic and eating habit.

Insulin can increase insulin-like growth factor 1 (IGF1) levels after consumption of high glycemic index and glycemic load. ${ }^{15,16}$ No association between glycemic index or glycemic load and IGF-1 in acne vulgaris subjects, was reported. ${ }^{17}$ There are several factors that affect acne vulgaris pathogenesis and lipid profile levels in the circulation, causing several characteristic variations on acne vulgaris.

\section{Conclusion}

In this study, there is no association between lipid profiles levels and acne vulgaris. Further research is needed to determine other parameters associated with pathogenesis of acne vulgaris.

\section{References}

1. Zaenglein AL, Graber EM, Thiboutot DM. Acne vulgaris and acneiform eruptions. In: Goldsmith LA, Katz SI, Gilchrest BA, Paller AS, Leffell DJ, Wolff K, editors. Fitzpatrick's Dermatology in General Medicine. 8th ed. New York: McGraw-Hill; 2012. p. $897-917$.

2. Arora MK, Seth S, Dayal S. The Relationship of Lipid Profile and Menstrual Cycle with Acne Vulgaris. Clin Biochem. 2010; 43(18): 1415-20.

3. Esmaeili H, Halimi M, Hagigi A. Gastrointestinal Dysfunction Symptoms and Lipids Profile in Patients with Various Severities of Acne Vulgaris. J Med Sci. 2014; 14(3): 130-6.

4. Das S, Reynolds RV. Recent Advances in Acne Pathogenesis: Implications for Therapy. Am J Clin Dermatol. 2014; 15(6): 479-88.
5. Cuddy L, Coulson I. Assessment and Recommended Treatment Options for Acne. Prescriber. 2014; 25(19): 19-26.

6. Katsambas AD, Cunliffe WJ, Zouboulis CC. Clinical Aspect of Acne Vulgaris. In: Zouboulis CC, Katsambas AD, Kligman AM, editors. Pathogenesis and Treatment of Acne and Rosacea. Berlin: SpringerVerlag Berlin Heidenberg; 2014. p.213-21.

7. Gollinick HP. From New Findings in Acne Pathogenesis to New Approaches in Treatment. J Eur Acad Dermatol Venereol. 2015; 29(Supll 5): 1-7.

8. Anggraini O, Simanungkalit R, Jusuf NK. Studi Retrospektif Pasien Akne Vulgaris di RSUP H. Adam Malik Medan Periode Tahun 2010-2012. Bandung: Kongres Nasional XIV Perdoski; 2014.

9. Camera E, Picardo M. Lipids in Serum and Sebum. In: Zoubolis CC, Katsambas AD, Kligman AM, editors. Pathogenesis and Treatment of Acne and Rosacea. Berlin: Springer-Verlag Berlin Heidenberg, 2014; p. 305-13.

10. Cunha MG, Batista AL, Macedo MS, Filho C, Fonseca F. Study of Lipid Profile in Adult Women with Acne. Clin Cosmet Investig Dermatol. 2015; 8 : 449-54.

11. El-Akawi Z, Abdel-Latif N, Abdul-Razzak K, Al-Aboosi M. The Relationship between Blood Lipids Profile and Acne. J Health Sci. 2007; 53(5): 596-9.

12. Ekiz O, Balta I, Unlu E, Sen BB, Rifaioglu EN, Dogramaci AC. Assessment of Thyroid Function and Lipid Profile in Patients with Postadolescent Acne in a Mediterranean Population from Turkey. Int J Dermatol. 2015; 54: 1376-81.

13. Bakry OA, El Shazly RM, El Farargy SM, Kotb D. Role of Hormones and Blood Lipids in The Pathogenesis of Acne Vulgaris in Nonobese, Non-hirsute Females. Indian Dermatol Online J. 2014; 5(Suppl 1): 9-16.

14. Jiang H, Li CY, Zhou L, Lu B, Lin Y, Huang X, et al. Acne Patients Frequently Associated with Abnormal Plasma Lipid Profile. J Dermatol. 2015; 42(3): 296-9.

15. Arora MK, Seth S, Dayal S, Trehan AS, Seth M. Serum Lipid Profile in Female Patients with Severe Acne Vulgaris. Clin Lab. 2014 60(7): 1201-5.

16. Berra B, Rizzo AM. Glycemic Index, Glycemic Load, Wellness and Beauty: The State of Art. Clin Dermatol. 2009; 27(2): 230-5.

17. Panjaitan RR, Tala ZZ, Jusuf NK. Hubungan antara Indeks Glikemik dan Beban Glikemik dengan Insulin-like Growth Factors-1 pada Pasien Akne Vulgaris. MDVI. 2011; 38: 7s-13s. 